\title{
Incidence, Mortality and Predictors of Acute Kidney Injury in Patients with Cirrhosis: A Systematic Review and Meta-analysis
}

\author{
Raseen Tariq ${ }^{1}$, Yousaf Hadi $^{2}$, Khusdeep Chahal ${ }^{3}$, Sivani Reddy ${ }^{3}$, Habeeb Salameh ${ }^{4}$ \\ and Ashwani K. Singal*5 \\ ${ }^{1}$ Department of Medicine, Rochester General Hospital, Rochester, NY, USA; ${ }^{2}$ Department of Medicine, University of West Virginia, \\ Morgantown, WV, USA; ${ }^{3}$ University of Alabama at Birmingham, Birmingham, AL, USA; ${ }^{4}$ Department of Gastroenterology, \\ University of Texas Medical Branch, Galveston, TX, USA; ${ }^{5}$ Division of Gastroenterology and Hepatology, University of South \\ Dakota, Sanford School of Medicine, Sioux Falls, SD, USA
}

\begin{abstract}
Background and Aims: Acute kidney injury (AKI) is common in patients with cirrhosis but the incidence is heterogeneous among studies. We performed a meta-analysis to describe the incidence of AKI and its impact on patient mortality in patients with cirrhosis. We also evaluated the admission variables predicting development of AKI. Methods: A systematic search of various databases was performed up to November 2018. Meta-analyses were performed using random effects models. Results: Of 18,474 patients with cirrhosis from 30 selected studies, 5,648 developed AKI, with a pooled incidence of $29 \%$ ( $95 \%$ confidence interval [CI]: $28-$ $30 \%, I^{2}$ of $99 \%$ ). In-hospital mortality assessed in eight studies was six-fold higher among AKI patients, as compared to those without AKI (odds ratio [OR] 6.72, 95\% CI: 3.47-13, $p<0.0001, I^{2}$ of $\left.70 \%\right)$. Three studies on patients admitted to intensive care showed about six-fold higher mortality among AKI patients (OR 5.90, 95\% CI: 3.21-10.85, p>0.0001). Mortality remained significantly high, at days 30 and 90 and even at 1-year follow up after development of AKI. Of 12 admission variables analyzed, model for end-stage liver disease score, Child-Pugh-Turcotte stage $C$, presence of ascites, and presence of sepsis/septic shock were statistically significant risk factors for AKI. Conclusions: AKI occurred in about $29 \%$ of patients with cirrhosis and is associated with a six-fold increased risk of in-hospital mortality. Mortality remained high even in long-term follow-up of 1 year. Patients at risk for AKI development can be recognized at admission. Prospective studies are needed to develop strategies for improving outcome of these patients.
\end{abstract}

Citation of this article: Tariq R, Hadi Y, Chahal K, Reddy S, Salameh $H$, Singal AK. Incidence, mortality and predictors of acute kidney injury in patients with cirrhosis: A systematic

Keywords: Acute kidney injury; Cirrhosis; Mortality; Outcomes.

Abbreviations: AKI, acute kidney injury; AKIN, AKI Acute Kidney Injury Network; CI, confidence interval; KDIGO, Kidney Disease Improving Global Outcomes; LFK, Luis Furuya-Kanamori; OR, odds ratio; RIFLE, risk injury and failure. Received: 18 December 2019; Revised: 4 February 2020; Accepted: 25 February 2020

*Correspondence to: Ashwani K. Singal, Avera University Hospital, University of South Dakota, Institute of Human Genetics Research, Sioux Falls, SD 57105, USA. Tel: +1-605-322-8545, Fax: +1-605-322-8536, E-mail: ashwanisingal. com@gmail.com review and meta-analysis. J Clin Transl Hepatol 2020; 8(2):135-142. doi: 10.14218/JCTH.2019.00060.

\section{Introduction}

Acute kidney injury (AKI) is a common event in the natural history of patients with cirrhosis, with an incidence rate varying from $14 \%$ to $50 \% .^{1-3}$ Furthermore, the diagnosis of AKI in patients with cirrhosis is confounded by fluid overload, ${ }^{4}$ the effect of bilirubin on the creatinine assays, and reduced muscle mass in patients with cirrhosis. ${ }^{5}$ Splanchnic pooling from portal hypertension in cirrhosis results in decreased effective circulating blood volume and renal blood flow, putting patients at risk for AKI and hepato-renal syndrome. ${ }^{6}$

The definition of AKI has changed over the last two decades, recognizing that an elevation in serum creatinine of $\geq 0.3 \mathrm{mg} / \mathrm{dL}$ from baseline negatively impacts survival. Many definitions have been introduced to define and stage AKI, such as the Risk Injury and Failure (commonly referred to as RIFLE), ${ }^{7}$ AKI Network (commonly referred to as AKIN) criteria, ${ }^{8}$ and Kidney Disease Improving Global Outcomes (commonly referred to as KDIGO). ${ }^{9}$ Variations in the definitions of AKI are one of the most important factors resulting in heterogeneity in the reported incidence of AKI among patients with cirrhosis. That being said, the essence of all the definitions of AKI seem to be similar. Although many studies have examined the incidence and impact on outcomes of AKI in patients with cirrhosis, pooled data from these studies is scarce. We performed this meta-analysis to pool the data from observational studies to define the incidence and etiology of AKI in patients with cirrhosis and its impact on patient survival. We also aimed to examine variables at baseline that could identify patients with cirrhosis who are at risk of developing AKI.

\section{Methods}

\section{Study selection criteria}

The studies considered in this meta-analysis were casecontrol or prospective cohort studies of patients with cirrhosis, reporting on the incidence of AKI or/and comparing mortality among patients with versus those without AKI. 
Studies reporting mortality at short to medium term (inhospital, 30 days, and 90 days) or long-term (1 year) were included. Studies were excluded if they did not include incidence and/or mortality associated with AKI in cirrhotic patients or if there were insufficient data for analysis. Studies published only in English language and as full manuscripts were included in the analysis.

\section{Data sources and search strategy}

All procedures used in this meta-analysis were consistent with the PRISMA criteria for observational studies. ${ }^{10}$ We conducted a comprehensive search of Ovid MEDLINE, Embase, Cochrane Central Register of Controlled Trials, Cochrane Database of Systematic Reviews, Web of Science and Scopus, from January 1990 to November 2018. The search strategy was designed and conducted by experienced library staff. MeSH terms used in the search were 'acute kidney injury' or 'AKI' AND 'cirrhosis' AND 'risk factors' or 'incidence' or 'mortality'.

Two authors (R.T. and Y.H.) independently reviewed the titles and abstracts of the searched literature to identify potential studies for analysis. The full texts of these studies were reviewed for final selection to be included in the metaanalysis. The reference lists of articles with information on the topic were also reviewed for additional pertinent studies. Any discrepancy between these two investigators was resolved by joint re-evaluation of the article in question and consensus among the authors. A flow diagram of included studies is shown in Fig. 1.

The Newcastle-Ottawa scale was used independently by two investigators (R.T. and H.S.) to assess the quality of each selected study for the analysis. In this scale, observational studies were scored across three categories using the following parameters: selection (four questions), comparability (two questions), and ascertainment of the outcome of interest (three questions). For each question, 1 point was given if the study met the criterion, except for comparability of study

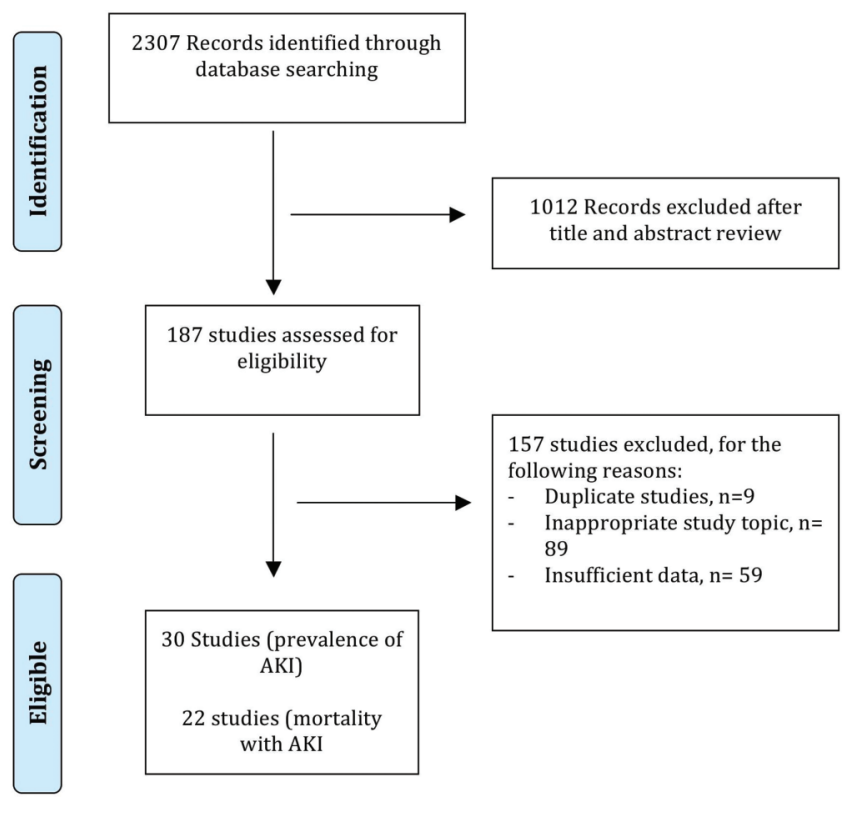

Fig. 1. Search strategy for included studies. groups, in which 2 points were awarded if the study controlled for age, sex, or both, and other confounding factors (Supplementary Table 1). Studies with a cumulative score of 7 or more were considered high quality and those with score of $\leq 6$ were considered of low quality. Any discrepancies were addressed by a joint re-evaluation of the article in question and consensus amongst the authors.

\section{Outcomes}

Our primary analysis focuses on the incidence and mortality associated with AKI in patients with cirrhosis. The secondary outcome was to evaluate the risk factors that predicted mortality in these patients

\section{Data abstraction}

Data were independently abstracted to a predetermined data collection Microsoft Excel spreadsheet by three investigators (R.T., Y.H and K.C.). For each study, data were collected for study design, location, year of publication, definition of AKI used, patient demographics, follow-up period, and outcomes. Conflicts on data abstraction were resolved by consensus amongst authors and referring to the original article.

\section{Statistical analyses}

The random-effects model described by DerSimonian and Laird $^{11}$ was used to calculate weighted incidence rate of AKI with corresponding $95 \%$ confidence interval (CI). Data were weighted based on sample size in each study. For mortality analysis at various time points, odds ratio (OR) with $95 \% \mathrm{CI}$ were derived on the odds of dying among AKI patients compared to those without AKI. To identify variables at baseline predictive of AKI risk, ORs were determined for categorical variables and mean difference for continuous variables.

We assessed heterogeneity within groups with the $I^{2}$ statistic, which estimates the proportion of total variation across studies. $I^{2}$ value $>50 \%$ suggested heterogeneity of the pooled data. ${ }^{12}$ To address heterogeneity, subgroup analyses were performed on studies defining AKI using the AKIN criteria, high quality studies, and prospective studies. Publication bias was assessed by visual inspection of funnel plots and numerically using the Luis Furuya-Kanamori (LFK) estimate on a Doi plot. The scoring was: no asymmetry when the LFK index was within \pm 1 ; minor asymmetry when the LFK index exceeded \pm 1 but was within \pm 2 ; major asymmetry when the LFK index exceeded \pm 2 . Publication bias was considered if the given analyses had major asymmetry on the inspection of funnel plots. If publication bias was found on funnel plot, we used the trim and fill for adjusting publication bias. ${ }^{12,13}$ All $p$ values were 2 -tailed and considered statistically significant if $<0.05$. Review Manager (version 5.3; Cochrane Inc.) and MetaXL, version 5.1 (EpiGear International Pty Ltd) statistical software program were used to analyze the pooled data (www.epigear.com).

\section{Results}

\section{Baseline characteristics of included studies}

On the initial literature search, 2307 potentially relevant studies were identified. After screening titles and abstracts, 187 full-text articles were reviewed for study selection. Of 
Tariq R. et al: Acute kidney injury and cirrhosis

Table 1. Baseline characteristics of included studies

\begin{tabular}{|c|c|c|c|c|c|c|c|c|}
\hline First author, year & $\begin{array}{l}\text { Study } \\
\text { type }\end{array}$ & $\begin{array}{l}\text { Location of } \\
\text { study }\end{array}$ & $\begin{array}{l}\text { Total, } \\
n\end{array}$ & $\begin{array}{l}\text { With } \\
\text { AKI, } \\
n\end{array}$ & $\begin{array}{l}\text { Mean } \\
\text { age }\end{array}$ & $\begin{array}{l}\% \\
\text { Males }\end{array}$ & $\begin{array}{l}\text { Follow-up } \\
\text { period }\end{array}$ & Definition of AKI \\
\hline Angeli, 2014 & $\mathrm{P}$ & Spain & 510 & 98 & 55 & 64.9 & 90 days & AKIN \\
\hline Bıyık, 2016 & RT & Turkey & 277 & 108 & 62.1 & 57.8 & 4 years & KDIGO criteria \\
\hline Bucsics, 2015 & RT & Austria & 239 & 78 & 54.9 & 66.9 & $\mathrm{n} / \mathrm{a}$ & AKIN \\
\hline Chen, 2011 & RT & Taiwan & 2,375 & 636 & 60.73 & 69.1 & 58 months & eGFR $<60$ \\
\hline Choi, 2014 & RT & Korea & 643 & 83 & 57.4 & 74.3 & & AKIN \\
\hline Cholongitas, 2009 & $P$ & UK & 312 & 128 & 49.3 & NA & 96 weeks & $\begin{array}{l}\text { Serum creatinine } \\
\geq 300 \mathrm{mmol} / \mathrm{L}\end{array}$ \\
\hline Cholongitas,2009b & RT & UK & 412 & 205 & 49.3 & 59.2 & 17 years & RIFLE \\
\hline de Araujo, 2014 & RT & Brazil & 46 & 20 & 56.94 & 63 & 13 months & AKIN \\
\hline du Cheyron, 2005 & RT & France & 186 & 73 & 56.4 & 69 & 5 years & ADQI definition \\
\hline Fagundes, 2013 & $\mathrm{P}$ & Spain & 375 & 177 & 61 & 62 & 25 months & AKIN \\
\hline Hampel, 2001 & RT & New Mexico & 93 & 23 & 57.5 & NA & 7 years & $\begin{array}{l}\uparrow \text { serum creatinine } \\
>1.0 \mathrm{mg} / \mathrm{dl}\end{array}$ \\
\hline Hseih, 2017 & RT & Taiwan & 117 & 46 & 61 & 72 & 6 weeks & ICA \\
\hline Huelin, 2017 & $\mathrm{P}$ & $\begin{array}{l}\text { Spain and } \\
\text { Italy }\end{array}$ & 547 & 290 & 61 & 67 & 90 days & ICA \\
\hline Hung, 2012 & RT & Taiwan & 2592 & 145 & 57.5 & 70.8 & 1 year & ICD-9-CM \\
\hline Jaques, 2018 & $P$ & Switzerland & 105 & 55 & 58.0 & 71.4 & 2 years & AKIN \\
\hline Jindal, 2015 & RT & India & 241 & 55 & 46.12 & 85.47 & 33 months & $\begin{array}{l}\text { Mild or moderate AKI } \\
\text { with cut-off creatinine } \\
\text { at } 3 \mathrm{mg} / \mathrm{dL}\end{array}$ \\
\hline Maiwall, 2015 & $P$ & India & 451 & 122 & 46 & 86 & 1 year & AKIN \\
\hline Marciano, 2017 & RT & Argentina & 108 & 37 & 61.5 & 59.6 & 3 years & KDIGO \\
\hline Nuthalapati, 2017 & RT & USA & 339 & 96 & 57.0 & 63 & 5 years & AKIN \\
\hline Pan, 2016 & $P$ & Taiwan & 242 & 152 & 58 & 75.7 & 2 years & AKIN and RIFLE \\
\hline Piano, 2013 & $P$ & Italy & 233 & 61 & 65.3 & 64.4 & NA & $\begin{array}{l}\text { AKIN \& conventional } \\
\text { criteria }\end{array}$ \\
\hline Prakash, 2011 & $P$ & India & 404 & 99 & 48.5 & 79 & 16 months & AKIN \\
\hline Scott, 2013 & $P$ & UK & 162 & 110 & 56.8 & 65.4 & 18 months & AKIN \\
\hline Shi, 2016 & RT & China & 1167 & 308 & NA & NA & 1 year & KDIGO \\
\hline Tandon, 2016 & RT & Canada & 4733 & 1850 & 60.4 & 64.3 & 10 years & KDIGO \\
\hline Tsien, 2013 & $P$ & Canada & 90 & 49 & 55.8 & 71.1 & 2 years & $\mathrm{n} / \mathrm{a}$ \\
\hline Warner, 2011 & RT & USA & 152 & 107 & 53 & $76 \%$ & 2 years & AKIN \\
\hline Wong, 2013 & $\mathrm{P}$ & USA & 337 & 166 & 55.91 & 56 & 30 days & ADQI definition \\
\hline Wong, 2017 & $P$ & $\begin{array}{l}\text { Multiple } \\
\text { centers in } \\
\text { North } \\
\text { America }\end{array}$ & 653 & 307 & 56.7 & 64 & 30 days & ICA \\
\hline Zhou, 2017 & RT & China & 333 & 60 & 55.68 & 63.06 & 2 years & KDIGO \\
\hline Summary & & & 18,474 & 5,648 & 56.8 & 66.9 & $\begin{array}{l}\text { Median: } \\
12 \text { months }\end{array}$ & NA \\
\hline
\end{tabular}

Abbreviations: ADQI, Acute Dialysis Quality Initiative; AKI, acute kidney injury; AKIN, AKI Network; ICA, International Club of Ascites; KDIGO, Kidney Disease Improving Global Outcomes; RIFLE, Risk Injury and Failure; P, prospective; RT, retrospective.

these, 30 studies $^{14-43}$ met eligibility criteria and were included for analysis and the remaining 157 were excluded for different reasons (Fig. 1). Of the 30 studies (12 prospective and 18 retrospective) analyzed and including 18,474 patients with cirrhosis (median age 57 years and $67 \%$ males), 16 were from the Western world (10 from Europe and 6 from USA or Canada) and the remaining studies were from Asia $(n=10)$, Middle East $(n=1)$, or South America $(n=3)$ 
(Table 1). The median Newcastle-Ottawa quality score for the included studies was 8 (range: 6-9) (Supplementary Table 1). A total of 17 studies were high quality and 13 were low quality. Other details and a summary of the included studies are described in Supplementary Table 2. The percentage of patients with baseline kidney dysfunction was not discussed in most studies, as shown in Supplementary Table 3; although, a majority of the studies included patients with some degree of baseline renal dysfunction.

\section{Incidence of AKI}

Of the 18,474 patients with cirrhosis in the 30 selected studies, 5,648 had developed AKI, with a pooled incidence of $29 \%$ (95\% CI: $28-30 \%$ ). AKI was defined based on the AKIN in 11 studies and the definition of AKI was variable in the remaining studies (Table 1 ). The pooled data had significant heterogeneity, with an $I^{2}$ of $99 \%$ and $p<0.0001$ (Fig. 2). No publication bias was seen on visual inspection of forest plot, with minor asymmetry on Doi plot (LFK=1.45) (Supplementary Fig. 1). Heterogeneity remained high when pooled incidence was analyzed only for prospective studies (40\%, 95\% CI: $38-41 \%)$, for studies that used AKIN criteria $(29 \%, 95 \%$ CI: $28-31 \%)$, and for studies with high quality $(40 \%, 95 \% \mathrm{CI}$ : $39-41 \%$ ) (Supplementary Fig. 2A, 1B and 1C, respectively). One study was performed before 2005 and in order to ensure the universal definitions of AKI after 2005, subgroup analysis was performed after the exclusion of that study, which revealed the same incidence of AKI $(29 \%, 95 \%$ CI: $28-$ $30 \%$ ) after exclusion of the above mentioned study. ${ }^{26}$

\section{Mortality risk: comparing patients with AKI vs. no AKI}

Of the 30 studies included, 22 reported patient mortality data for a median follow-up of 12 months (range: 30 days to 10 years) (Table 1). In-hospital mortality was assessed in eight studies. The rate of mortality among AKI patients was 215/

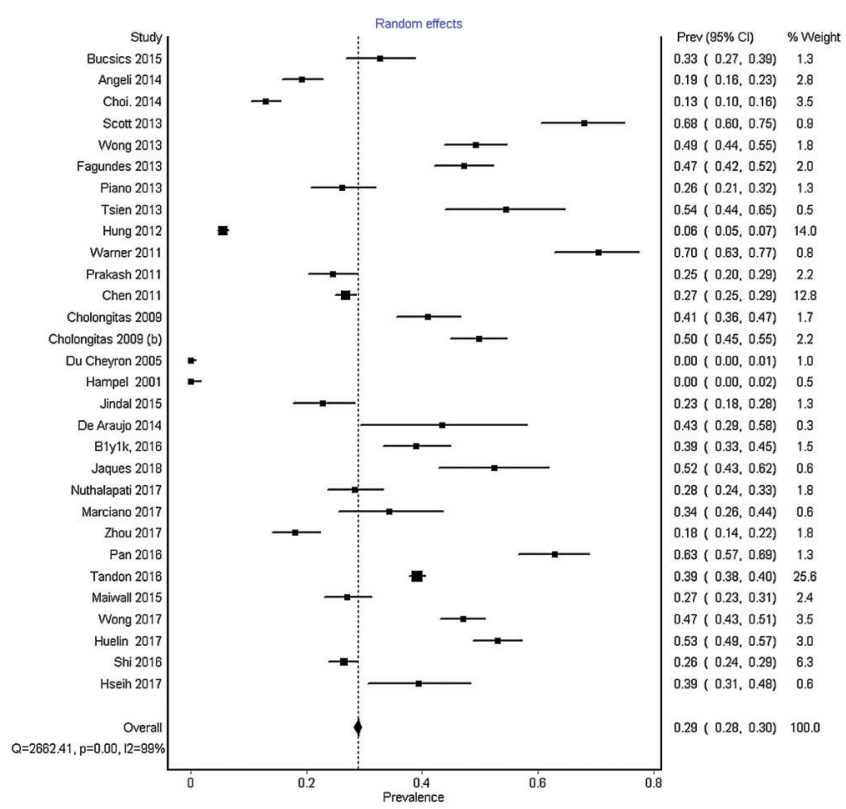

Fig. 2. Forest plot depicting pooled incidence of acute kidney injury in patients with cirrhosis.
$620(34.6 \%)$ vs. $61 / 624(9.7 \%)$, which was six-fold higher among AKI patients compared to those without AKI (OR [95\% $\mathrm{CI}]: 6.72[3.47-13], p<0.0001)$. Separate analysis from three studies on patients admitted to intensive care also showed about six-fold mortality among AKI patients (277/ $353(78 \%)$ vs. $154 / 387$ (39.7\%); OR [95\% CI]: 5.90 [3.21-10.85], $p>0.0001)$. Mortality at 30 days reported in seven studies was over three-fold higher with AKI (422/995 (42.4\%) vs. no AKI $841 / 3973(21.1 \%)$, OR [95\% CI]: 3.37 [2.35-4.84], $p>0.0001)$. Similarly, mortality remained higher at 90 days and at 1-year follow-up for those with compared to those without AKI (47.1\% vs. $16.4 \%$, OR [95\% CI]: 4.43 $[2.93-6.70], p>0.00001)$ and $(68.3 \%$ vs. $45.1 \%$, OR [ $95 \%$ CI]: 5.37 [2.45-11.79], $p>0.00001)$. However, there was significant heterogeneity for all the analyses (Fig. 3 A-E). No publication bias was seen on visual inspection of forest plots (Supplementary Fig. 3 A-E).

\section{Risk factors associated with development of AKI}

A total of 12 variables at admission were analyzed among 22 studies as predictors for the development of AKI. Of these, four predicted the risk of AKI, given as OR ( $95 \% \mathrm{CI})$ : model for end-stage liver disease score, 5.89 (5.17-6.62); ChildPugh-Turcotte stage C, 2.51 (1.83-3.44); presence of ascites, 2.06 (1.25-3.41); and presence of sepsis/septic shock, 2.72 (1.05-7.06) (Fig. 4 A-D). Interestingly, history of variceal bleed was associated with a decreased risk of AKI, 0.69 (0.48-0.99) (Fig. 4E). Other factors, including etiology of cirrhosis (alcoholic and viral), encephalopathy, bacterial infection on admission, male sex, age, and diabetes mellitus were not associated with risk of AKI (Supplementary Fig. 3A-G).

\section{Discussion}

The main findings of this meta-analysis on pooled data from 30 studies of patients with cirrhosis are a high incidence of AKI (at $29 \%$ ) and higher mortality during hospitalization and on follow-up to 1 year among patients who develop AKI when compared to those who do not. Further, patients at risk of development of AKI can be identified at presentation or hospitalization with higher model for end-stage liver disease or Child-Pugh-Turcotte score with ascites and/or sepsis/shock.

Portal hypertension with resultant splanchnic pooling of blood in patients with cirrhosis results in decreased effective circulating blood volume, setting the stage for development of AKI with decompensation of cirrhosis or introduction of any precipitant, such as volume loss, use of diuretics, administration of radio-contrast agents or nephrotoxic drugs, and onset of infections or sepsis. ${ }^{44}$ Cirrhosis is the 12 th leading cause of mortality in the general population, with over 40,000 annual deaths from this disease. ${ }^{45}$ In one study, mortality rate among patients with cirrhosis was over $20 \%$ at 2 years. ${ }^{46}$ Not only does AKI portend a worse prognosis in these patients but the mortality risk remains elevated in these patients at 1-year follow-up among those surviving the index hospitalization or development of event. Data in the current literature regarding renal recovery and its effect on mortality is scant, but a recent study shows a high mortality rate (of $15 \%$ ) in cirrhosis patients who experienced complete renal recovery after an AKI episode, as observed in the current analysis. ${ }^{15}$ Clearly, AKI represents a significant event in the natural course of these patients with cirrhosis, and this may be viewed as a sixth stage in the already five-stage 
Tariq R. et al: Acute kidney injury and cirrhosis

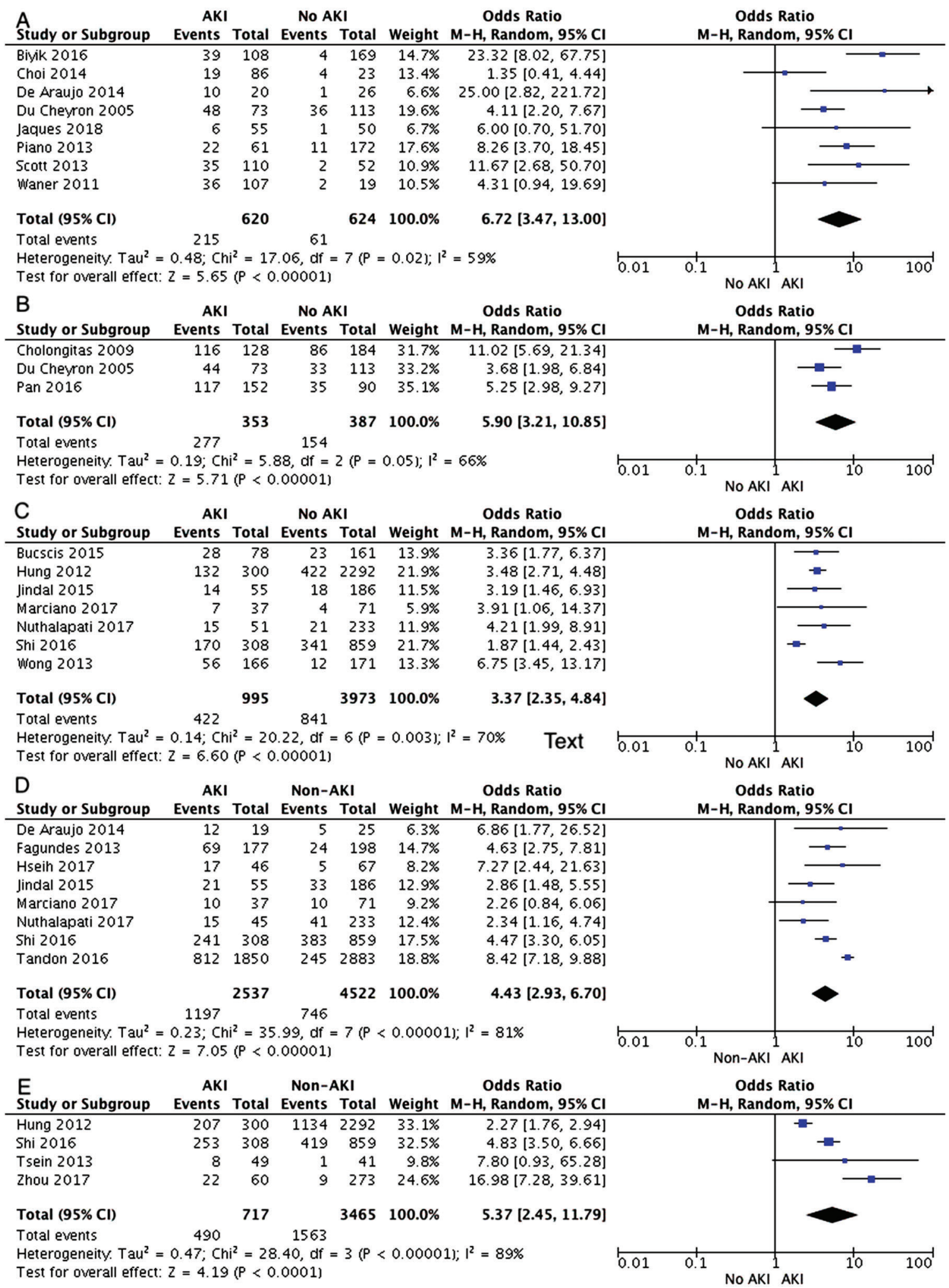

Fig. 3. Forest plots on mortality outcomes comparing cirrhosis patients with acute kidney injury vs. without acute kidney injury for A) overall in-hospital mortality, B) in-hospital mortality for intensive care patients, C) mortality at 30 days follow-up, D) mortality at 90 days follow-up, E) mortality at 1-year follow-up. 
Tariq R. et al: Acute kidney injury and cirrhosis

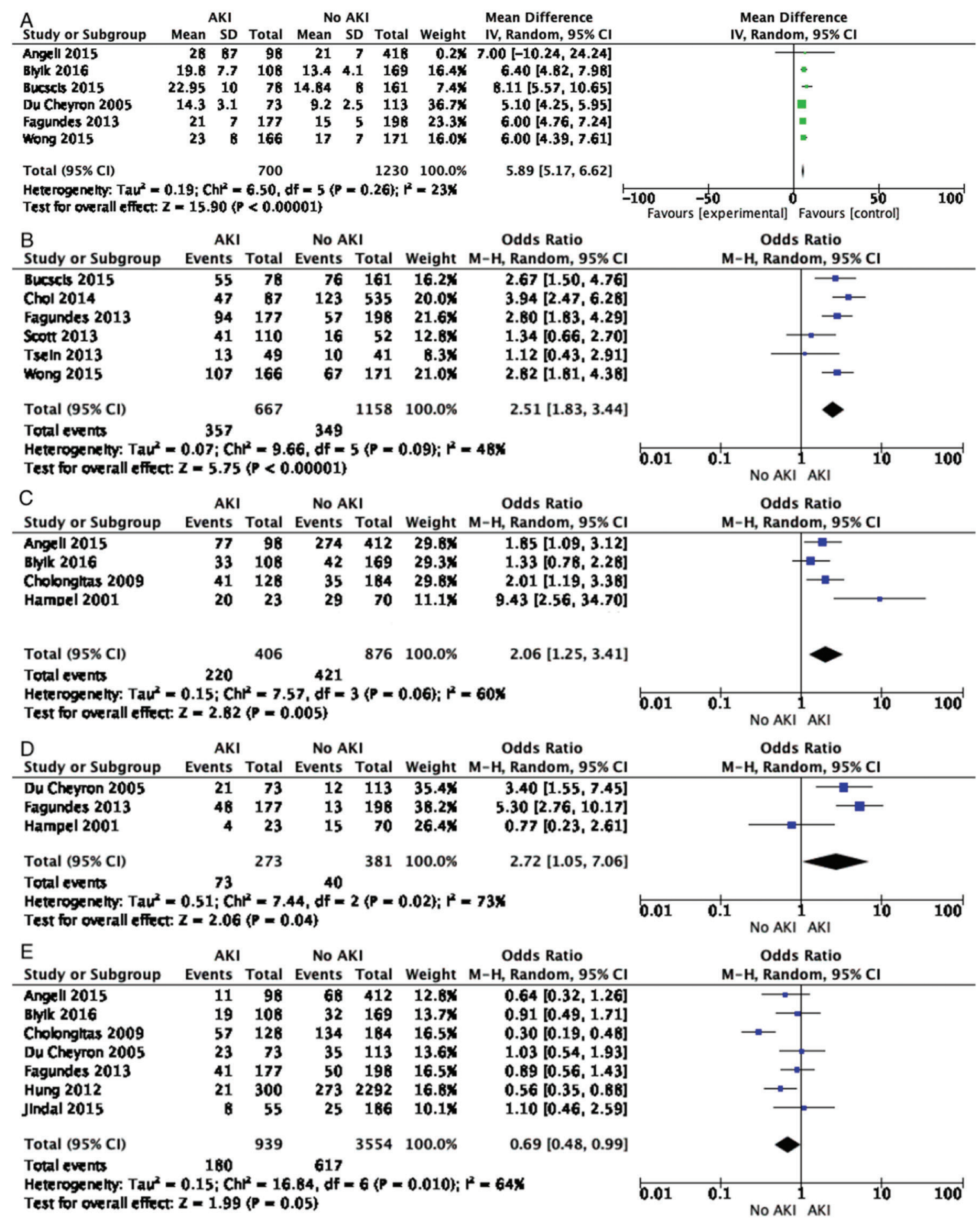

Fig. 4. Forest plots showing admission variables predicting acute kidney injury.

A) Model for end-stage liver disease score, B) Child-Pugh-Turcotte score, C) presence of ascites, and D) presence of sepsis/septic shock. Risk of acute kidney injury is reduced among patients with variceal bleeding $(\mathrm{E})$.

model of cirrhosis, with linear increase in short-term and long-term mortality. ${ }^{47}$ It has been shown in prospective studies that the index episode of AKI is a risk factor for subsequent episodes of AKI. ${ }^{48}$ With each episode of AKI, the renal reserve declines due to the inability of kidneys to recover function completely to original baseline level and resulting in risk for development of chronic kidney disease and impacting the outcomes negatively. ${ }^{31,33}$ 
While patients with cirrhosis constitute a heterogeneous cohort, the subpopulations at an increased risk of developing AKI have not been sufficiently studied. In our pooled analysis, model for end-stage liver disease score, ChildPugh stage, presence of ascites, and presence of severe sepsis/septic shock were associated with an elevated risk of developing an AKI. Severe sepsis/septic shock has been studied as independent risk factors for developing AKI regardless of cirrhosis. Also, association of AKI with model for end-stage liver disease score and Child-Pugh class found in our study are in line with the prior studies. ${ }^{48-50}$ Model for end-stage liver disease score is the most frequently used score all over the world to estimate patient outcomes and survival among patients with cirrhosis. Renal function apart from serum bilirubin and coagulation status is an important component of the model for end-stage liver disease score. Use of diuretics, large volume paracenteses, and fear of physicians to give volume expansion are some speculated reasons explaining higher risk of AKI in patients with ascites. ${ }^{51}$ Interestingly, presence of a history of or current admission with a variceal bleed was associated with a decreased risk of AKI. Patients with variceal bleeding receive antibiotics for spontaneous bacterial peritonitis prophylaxis, as recommended by guidelines from major societies; this use of spontaneous bacterial peritonitis prophylaxis may be the reason for lower incidence of AKI in this cohort. ${ }^{52}$ Diabetes and the etiology of cirrhosis were not found to be associated with AKI.

Pooled data on a large patient population with cirrhosis is the strength of this meta-analysis. Furthermore, our study also identified the predictors of AKI apart from pooled incidence and risk of mortality. However, our study does have some limitations. Studies included in our meta-analysis varied on study design, patient population, and status of cirrhosis, resulting in significant heterogeneity. Pooled data using the individual patient data from these studies may potentially overcome this limitation and provide more homogeneous data on incidence, impact on outcomes, and variables predictive of AKI. Furthermore, due to the very limited data available in the included studies regarding the mortality rates among subgroups with different stages of AKI, we could not perform a pooled mortality analysis based on severity of AKI. To explore the heterogeneity, meta-regression was considered with various predictor variables including sex, viral cirrhosis, alcoholic cirrhosis, Child-Pugh score, concomitant diabetes, presence of ascites, variceal bleeding, encephalopathy, bacterial infection, septic shock/ sepsis, mean difference in age and model for end-stage liver disease scores. The number of studies in each individual analysis was limited (all <10). Moreover, information for each predictor variable was also poorly present. At most, one predictor (sex) was present for three studies in one outcome (30-day mortality); the rest were present for one or two studies only. Hence, meta-regression was not performed based on poor information availability of predictorvariables. ${ }^{53}$

In conclusion, AKI is common in cirrhotic patients, and leads to increased mortality among patients admitted to hospital in the wards as well as in the ICU, which remained high even at long-term follow-up at 1 year. Multicenter prospective studies are also suggested using pre-defined criteria to define AKI, study outcomes, and risk factor variables as basis for development of homogeneous data.

\section{Funding}

None to declare.

\section{Conflict of interest}

The authors have no conflict of interests related to this publication.

\section{Author contributions}

Contributed to concept, data interpretation drafting and revision of manuscript (RT, AKS), data collection, drafting and revision of manuscript $(\mathrm{YH})$, data collection and interpretation (KS), and data collection (SR, HS).

\section{References}

[1] Russ KB, Stevens TM, Singal AK. Acute kidney injury in patients with cirrhosis. J Clin Transl Hepatol 2015;3:195-204. doi: 10.14218/JCTH.2015. 00015 .

[2] Montoliu S, Ballesté B, Planas R, Alvarez MA, Rivera M, Miquel M, et al. Incidence and prognosis of different types of functional renal failure in cirrhotic patients with ascites. Clin Gastroenterol Hepatol 2010;8:616-622. doi: 10. 1016/j.cgh.2010.03.029.

[3] Wu CC, Yeung LK, Tsai WS, Tseng CF, Chu P, Huang TY, et al. Incidence and factors predictive of acute renal failure in patients with advanced liver cirrhosis. Clin Nephrol 2006;65:28-33. doi: 10.5414/cnp65028.

[4] Wong F, Nadim MK, Kellum JA, Salerno F, Bellomo R, Gerbes A, et al. Working Party proposal for a revised classification system of renal dysfunction in patients with cirrhosis. Gut 2011;60:702-709. doi: 10.1136/gut.2010. 236133.

[5] Spencer K. Analytical reviews in clinical biochemistry: the estimation of creatinine. Ann Clin Biochem 1986;23:1-25. doi: 10.1177/000456328602300101.

[6] Ginès P, Schrier RW. Renal failure in cirrhosis. N Engl J Med 2009;361:12791290. doi: 10.1056/NEJMra0809139.

[7] Bellomo R, Ronco C, Kellum JA, Mehta RL, Palevsky P. Acute renal failure definition, outcome measures, animal models, fluid therapy and information technology needs: the Second International Consensus Conference of the Acute Dialysis Quality Initiative (ADQI) Group. Crit Care 2004;8:R204R212. doi: $10.1186 / \mathrm{cc} 2872$.

[8] Mehta RL, Kellum JA, Shah SV, Molitoris BA, Ronco C, Warnock DG, et al. Acute Kidney Injury Network: report of an initiative to improve outcomes in acute kidney injury. Crit Care 2007;11:R31. doi: 10.1186/cc5713.

[9] Khwaja A. KDIGO clinical practice guidelines for acute kidney injury. Nephron Clin Pract 2012;120:c179-c184. doi: 10.1159/000339789.

[10] Stroup DF, Berlin JA, Morton SC, Olkin I, Williamson GD, Rennie D, et al. Meta-analysis of observational studies in epidemiology: a proposal for reporting. Meta-analysis of Observational Studies in Epidemiology (MOOSE) group. JAMA 2000;283:2008-2012. doi: 10.1001/jama.283.15. 2008.

[11] DerSimonian R, Laird N. Meta-analysis in clinical trials. Control Clin Trials 1986;7:177-188. doi: 10.1016/0197-2456(86)90046-2.

[12] Easterbrook PJ, Berlin JA, Gopalan R, Matthews DR. Publication bias in clinical research. Lancet 1991;337:867-872. doi: 10.1016/0140-6736(91) 90201-y.

[13] Duval S, Tweedie R. Trim and fill: A simple funnel-plot-based method of testing and adjusting for publication bias in meta-analysis. Biometrics 2000;56:455-463. doi: 10.1111/j.0006-341 ×.2000.00455.x.

[14] Scott RA, Austin AS, Kolhe NV, McIntyre CW, Selby NM. Acute kidney injury is independently associated with death in patients with cirrhosis. Frontline Gastroenterol 2013;4:191-197. doi: 10.1136/flgastro-2012-100291.

[15] Wong F, O'Leary JG, Reddy KR, Patton H, Kamath PS, Fallon MB, et al. New consensus definition of acute kidney injury accurately predicts 30-day mortality in patients with cirrhosis and infection. Gastroenterology 2013;145: 1280-1288.e1. doi: 10.1053/j.gastro.2013.08.051.

[16] Fagundes C, Barreto R, Guevara M, Garcia E, Solà E, Rodríguez E, et al. A modified acute kidney injury classification for diagnosis and risk stratification of impairment of kidney function in cirrhosis. J Hepatol 2013;59:474-481. doi: 10.1016/j.jhep.2013.04.036.

[17] Piano S, Rosi S, Maresio G, Fasolato S, Cavallin M, Romano A, et al. Evaluation of the Acute Kidney Injury Network criteria in hospitalized patients with 
cirrhosis and ascites. J Hepatol 2013;59:482-489. doi: 10.1016/j.jhep. 2013.03.039.

[18] Tsien CD, Rabie R, Wong F. Acute kidney injury in decompensated cirrhosis. Gut 2013;62:131-137. doi: 10.1136/gutjnl-2011-301255.

[19] Hung TH, Tsai CC, Hsieh YH, Tsai CC, Tseng CW, Tsai JJ. Effect of renal impairment on mortality of patients with cirrhosis and spontaneous bacterial peritonitis. Clin Gastroenterol Hepatol 2012;10:677-681. doi: 10.1016/j.cgh 2012.02.026.

[20] Warner NS, Cuthbert JA, Bhore R, Rockey DC. Acute kidney injury and chronic kidney disease in hospitalized patients with cirrhosis. J Investig Med 2011;59:1244-1251. doi: 10.2130/JIM.0b013e3182321471.

[21] Prakash J, Mahapatra AK, Ghosh B, Arora P, Jain AK. Clinical spectrum of renal disorders in patients with cirrhosis of liver. Ren Fail 2011;33:40-46. doi: 10.3109/0886022X.2010.541582.

[22] Chen YW, Wu CJ, Chang CW, Lee SY, Sun FJ, Chen HH. Renal function in patients with liver cirrhosis. Nephron Clin Pract 2011;118:c195-c203. doi: $10.1159 / 000321384$.

[23] Cholongitas E, Senzolo M, Patch D, Shaw S, O'Beirne J, Burroughs AK. Cirrhotics admitted to intensive care unit: the impact of acute renal failure on mortality. Eur J Gastroenterol Hepatol 2009;21:744-750. doi: 10. 1097/MEG.0b013e328308bb9c.

[24] Cholongitas E, Calvaruso V, Senzolo M, Patch D, Shaw S, O'Beirne J, et al. RIFLE classification as predictive factor of mortality in patients with cirrhosis admitted to intensive care unit. J Gastroenterol Hepatol 2009;24:16391647. doi: 10.1111/j.1440-1746.2009.05908.x.

[25] du Cheyron D, Bouchet B, Parienti JJ, Ramakers M, Charbonneau P. The attributable mortality of acute renal failure in critically ill patients with liver cirrhosis. Intensive Care Med 2005;31:1693-1699. doi: 10.1007/s00134005-2842-7.

[26] Hampel H, Bynum GD, Zamora E, El-Serag HB. Risk factors for the development of renal dysfunction in hospitalized patients with cirrhosis. Am J Gastroenterol 2001;96:2206-2210. doi: 10.1111/j.1572-0241.2001.03958.x.

[27] Jindal A, Bhadoria AS, Maiwall R, Sarin SK. Evaluation of acute kidney injury and its response to terlipressin in patients with acute-on-chronic liver failure. Liver Int 2016;36:59-67. doi: 10.1111/liv.12895.

[28] de Araujo A, Alvares-da-Silva MR. Akin criteria as a predictor of mortality in cirrhotic patients after spontaneous bacterial peritonitis. Ann Hepatol 2014; 13:390-395. doi: 10.1016/S1665-2681(19)30870-1.

[29] Bıyık M, Ataseven H, Bıyık Z, Asil M, Çifçi S, Sayın S, et al. KDIGo (Kidney Disease: Improving Global Outcomes) criteria as a predictor of hospital mortality in cirrhotic patients. Turk J Gastroenterol 2016;27:173-179. doi: 10. 5152/tjg.2016.15467.

[30] Jaques DA, Spahr L, Berra G, Poffet V, Lescuyer P, Gerstel E, et al. Biomarkers for acute kidney injury in decompensated cirrhosis: A prospective study. Nephrology (Carlton) 2019;24:170-180. doi: 10.1111/nep.13226.

[31] Nuthalapati A, Schluterman N, Khanna A, Greenberg D, Thuluvath PJ. Impact of acute kidney injury on mortality of patients hospitalized for complications of cirrhosis. J Clin Exp Hepatol 2017;7:290-299. doi: 10.1016/j.jceh.2017. 05.004 .

[32] Marciano S, Mauro E, Dirchwolf M, Debernardi ME, Giunta D, Pagotto V, et al. A Dynamic Definition of Acute Kidney Injury Does not Improve Prognosis Assessment in Acutely Decompensated Patients with Cirrhosis. J Clin Exp Hepatol 2017;7:135-143. doi: 10.1016/j.jceh.2017.03.004.

[33] Zhou F, Luo Q, Han L, Yan H, Zhou W, Wang Z, et al. Evaluation of absolute serum creatinine changes in staging of cirrhosis-induced acute renal injury and its association with long-term outcomes. Kidney Blood Press Res 2017; 42:294-303. doi: 10.1159/000477529.

[34] Pan HC, Chien YS, Jenq CC, Tsai MH, Fan PC, Chang CH, et al. Acute kidney injury classification for critically Ill cirrhotic patients: A comparison of the KDIGO, AKIN, and RIFLE classifications. Sci Rep 2016;6:23022. doi: 10. 1038/srep23022.

[35] Tandon P, James MT, Abraldes JG, Karvellas CJ, Ye F, Pannu N. Relevance of new definitions to incidence and prognosis of acute kidney injury in hospitalized patients with cirrhosis: A retrospective population-based cohort study. PLoS One 2016;11:e0160394. doi: 10.1371/journal.pone.0160394.
[36] Maiwall R, Kumar S, Chandel SS, Kumar G, Rastogi A, Bihari C, et al. AKI in patients with acute on chronic liver failure is different from acute decompensation of cirrhosis. Hepatol Int 2015;9:627-639. doi: 10.1007/s12072-0159653-x.

[37] Bucsics T, Mandorfer M, Schwabl P, Bota S, Sieghart W, Ferlitsch A, et al. Impact of acute kidney injury on prognosis of patients with liver cirrhosis and ascites: A retrospective cohort study. J Gastroenterol Hepatol 2015; 30:1657-1665. doi: 10.1111/jgh.13002.

[38] Angeli P, Rodríguez E, Piano S, Ariza X, Morando F, Solà E, et al. Acute kidney injury and acute-on-chronic liver failure classifications in prognosis assessment of patients with acute decompensation of cirrhosis. Gut 2015;64: 1616-1622. doi: 10.1136/gutjnl-2014-307526.

[39] Choi YJ, Kim JH, Koo JK, Lee CI, Lee JY, Yang JH, et al. Prevalence of renal dysfunction in patients with cirrhosis according to ADQI-IAC working party proposal. Clin Mol Hepatol 2014;20:185-191. doi: 10.3350/cmh.2014.20.2. 185.

[40] Wong F, O'Leary JG, Reddy KR, Garcia-Tsao G, Fallon MB, Biggins SW, et al. Acute kidney injury in cirrhosis: Baseline serum creatinine predicts patient outcomes. Am J Gastroenterol 2017;112:1103-1110. doi: 10.1038/ajg. 2017.122.

[41] Huelin P, Piano S, Solà E, Stanco M, Solé C, Moreira R, et al. Validation of a staging system for acute kidney injury in patients with cirrhosis and association with acute-on-chronic liver failure. Clin Gastroenterol Hepatol 2017; 15:438-445.e5. doi: 10.1016/j.cgh.2016.09.156.

[42] Shi X, Zhu P, Yan G, Liu C, Zhang C, Huang G, et al. Clinical characteristics and long-term outcome of acute kidney injury in patients with HBV-related acute-on-chronic liver failure. J Viral Hepat 2016;23:920-929. doi: 10. $1111 /$ jvh. 12566.

[43] Hsieh YC, Lee KC, Chen PH, Su CW, Hou MC, Lin HC. Acute kidney injury predicts mortality in cirrhotic patients with gastric variceal bleeding. J Gastroenterol Hepatol 2017;32:1859-1866. doi: 10.1111/jgh.13777.

[44] Kamath PS, Wiesner RH, Malinchoc M, Kremers W, Therneau TM, Kosberg CL, et al. A model to predict survival in patients with end-stage liver disease. Hepatology 2001;33:464-470. doi: 10.1053/jhep.2001.22172.

[45] Xu J, Murphy SL, Kochanek KD, Bastian B, Arias E. Deaths: Final data for 2016. Natl Vital Stat Rep 2018;67:1-76.

[46] Scaglione S, Kliethermes S, Cao G, Shoham D, Durazo R, Luke A, et al. The epidemiology of cirrhosis in the United States: A population-based study. J Clin Gastroenterol 2015;49:690-696. doi: 10.1097/MCG.0000000000000208.

[47] Arvaniti V, D’Amico G, Fede G, Manousou P, Tsochatzis E, Pleguezuelo M, et al. Infections in patients with cirrhosis increase mortality four-fold and should be used in determining prognosis. Gastroenterology 2010;139: 1246-1256, 1256.e1-5. doi: 10.1053/j.gastro.2010.06.019.

[48] Singal AK, Jackson B, Pereira GB, Russ KB, Fitzmorris PS, Kakati D, et al. Biomarkers of renal injury in cirrhosis: Association with acute kidney injury and recovery after liver transplantation. Nephron 2018;138:1-12. doi: 10. $1159 / 000479074$.

[49] Romano TG, Schmidtbauer I, Silva FM, Pompilio CE, D'Albuquerque LA, Macedo E. Role of MELD score and serum creatinine as prognostic tools for the development of acute kidney injury after liver transplantation. PLoS One 2013;8:e64089. doi: 10.1371/journal.pone.0064089.

[50] Barreto AG, Daher EF, Silva Junior GB, Garcia JH, Magalhães CB, Lima JM, et al. Risk factors for acute kidney injury and 30-day mortality after liver transplantation. Ann Hepatol 2015;14:688-694. doi: 10.1016/S1665-2681(19) 30763-X.

[51] Unger LW, Stork T, Bucsics T, Rasoul-Rockenschaub S, Staufer K, Trauner M, et al. The role of TIPS in the management of liver transplant candidates. United European Gastroenterol J 2017;5:1100-1107. doi: 10. $1177 / 2050640617704807$.

[52] Garcia-Tsao G, Sanyal AJ, Grace ND, Carey W. Prevention and management of gastroesophageal varices and variceal hemorrhage in cirrhosis. Hepatology 2007;46:922-938. doi: 10.1002/hep.21907.

[53] Deeks J], Higgins JPT, Altman DG. Chapter 10: Analysing data and undertaking meta-analyses. Available from: https://training.cochrane.org/handbook/current/chapter-10\# section-10-11. 